\title{
Reversing the Irreversible: Thermodynamic Stabilization of Lithium Aluminum Hydride Nanoconfined Within a Nitrogen-Doped Carbon Host
}

\section{YongJun Cho}

Korea Advanced Institute of Science and Technology (KAIST)

Sichi Li

Lawrence Livermore National Laboratory

Jonathan Snider

Sandia National Laboratories

Maxwell Marple

Lawrence Livermore National Laboratory

Nicholas Strange

SLAC National Accelerator Laboratory

Joshua Sugar

Sandia National Laboratories

\section{Farid El Gabaly}

Sandia National Laboratories

Andreas Schneemann

Sandia National Laboratories

Sungsu Kang

Seoul National University

Min-ho Kang

Center for Nanoparticle Research, Institute for Basic Science (IBS), Republic of Korea Hayoung Park

Seoul National University

Jungwon Park

Seoul National University https://orcid.org/0000-0003-2927-4331

\section{Liwen Wan}

Lawrence Berkeley National Laboratory

\section{Harris Mason}

Lawrence Livermore National Laboratory https://orcid.org/0000-0002-1840-0550

\section{Mark Allendorf}

Sandia National Laboratories https://orcid.org/0000-0001-5645-8246

\section{Brandon Wood}


Lawrence Livermore National Laboratory

\section{Eun Seon Cho}

Korea Advanced Institute of Science and Technology (KAIST)

Vitalie Stavila ( $\square$ vnstavi@sandia.gov )

Sandia National Laboratories https://orcid.org/0000-0003-0981-0432

\section{Article}

Keywords: Nanoconfinement, Metastable Materials, Metal Hydrides, Porous Carbons, Hydrogen Storage, Coordination Chemistry

Posted Date: January 29th, 2021

DOl: https://doi.org/10.21203/rs.3.rs-141693/v1

License: (c) (1) This work is licensed under a Creative Commons Attribution 4.0 International License. Read Full License 


\section{Abstract}

A general problem when designing functional nanomaterials for energy storage is the lack of control over the stability and reactivity of metastable phases. Using the high-capacity hydrogen storage candidate $\mathrm{LiAlH}_{4}$ as an exemplar, we demonstrate a new approach to thermodynamic stabilization of metastable metal hydrides by coordination to nitrogen binding sites within the nanopores of $\mathrm{N}$-doped CMK-3 carbon (NCMK-3). The resulting LiAlH ${ }_{4} @ N C M K-3$ material releases $\mathrm{H}_{2}$ at temperatures as low as $126{ }^{\circ} \mathrm{C}$ with full decomposition below $240{ }^{\circ} \mathrm{C}$, bypassing the usual $\mathrm{Li}_{3} \mathrm{AlH}_{6}$ intermediate. Moreover, $>80 \%$ of $\mathrm{LiAlH}_{4}$ can be regenerated under $100 \mathrm{MPa} \mathrm{H}_{2}$, a feat previously thought to be impossible. The nitrogen sites lower the energy barrier for regenerating the hydride by changing the density of states in the vicinity of the Fermi level, effectively acting as solvation sites for lithium ions. Theoretical calculations provide a rationale for the unprecedented solid-state reversibility, which derives from the combined effects of nanoconfinement, Li adatom formation, and charge redistribution between the metal hydride and the host.

\section{Main Text}

The increasing demand for improved materials with complex functionalities requires new approaches that can expand the range of accessible phases through rational incorporation of metastability into materials design. ${ }^{1}$ Metastable materials have become one of the main pillars in advancing novel concepts and transformative technologies in batteries, ${ }^{2}$ supercapacitors, ${ }^{3}$ piezoelectrics, ${ }^{4}$ optoelectronics, ${ }^{5}$ and heterogeneous catalysis. ${ }^{6}$ In contrast, in the area of materials-based hydrogen storage, metastability has yet to be fully leveraged and in fact has been a major barrier towards practical applications. Metastable hydrogen storage materials, such as $\mathrm{NH}_{3} \mathrm{BH}_{3},{ }^{7}$ metal amidoboranes, ${ }^{7} \mathrm{LiAlH}_{4}{ }^{8}$ and $\mathrm{AlH}_{3}{ }^{9}$ offer high volumetric and gravimetric energy densities, ${ }^{10}$ but have unfavorable thermodynamics of hydrogen release, and can only be rendered reversible using solution chemistries that require complex and energy intensive off-board regeneration. $7,9,11-15$ On top of disadvantageous thermodynamics, these materials often suffer from sluggish hydrogen release kinetics, which has discouraged their consideration as viable on-board vehicular storage candidates. ${ }^{16}$

Nanoscaling is a well-known strategy for improving the properties of metal hydrides, but it has been almost exclusively used to destabilize materials that are too thermodynamically stable, with the most dramatic effects being kinetic rather than thermodynamic in nature. ${ }^{16}$ Most efforts to date have been focused on nanoconfinement within nanoporous hosts to limit the hydride particle size. $16,17,18-22$ Carbons and carbon-based materials are by far the most common host materials, as they are lightweight and display remarkable chemical and thermal stability under conditions required to achieve reversible $\mathrm{H}_{2}$ release. ${ }^{16,17,23}$ Apart from utilizing the pores for maintaining nanoparticle size, recent studies by Carr et al. show that the incorporation of heteroatoms in carbon affects the kinetics and desorption pathway of the hydride, making the host material an active participant in the reaction process. ${ }^{24,25} \mathrm{An}$ important advantage of metastable hydrides is that, unlike most binary and complex metal hydrides, very little 
thermal input is required for hydrogen release. We hypothesize that nanoconfinement can provide a chemical environment similar to the one found in solid adducts of metastable metal hydrides that have shown stabilizing success (for example $\mathrm{LiAlH}_{4}$-dimethylether adduct ${ }^{26}$ ). By analogy, we reason that functionalities capable of inducing charge redistribution between the host and the metal hydride can thermodynamically stabilize metal hydrides and render them reversible.

Here, we report a new thermodynamic stabilization concept in which metastable $\mathrm{LiAlH}_{4}$ is nanoconfined within the pores of nitrogen-doped CMK-type carbons. We selected $\mathrm{LiAlH}_{4}$ for this investigation because of its high gravimetric hydrogen capacity $\left(10.6 \mathrm{wt}\right.$. \%) and pure hydrogen release upon mild heating. ${ }^{27,28}$ In bulk, the thermally induced hydrogen release from $\mathrm{LiAlH}_{4}$ comprises three decomposition steps (Table 1), the first of which is exothermic $\left(-10 \mathrm{~kJ} \mathrm{~mol}^{-1} \mathrm{H}_{2}\right)$, which makes rehydriding infeasible. ${ }^{29}$ In this work, we demonstrate that reversibility in $\mathrm{LiAlH}_{4}$ can be enabled by nanoconfinement within a $\mathrm{N}$-doped carbon scaffold. The resulting nanoconfined $\mathrm{LiAlH}_{4}$ material can be regenerated without resorting to complex solution-phase chemistry, opening the door to reconsideration of other high-capacity light metal hydrides that were previously considered unusable for practical applications. These results and the accompanying foundational understanding indicate that "thermodynamic stabilization" of metastable metal hydrides is a viable approach to hydrogen storage, presenting a new strategy for enabling reversibility through guesthost interactions.

\section{Infiltration of $\mathrm{LiAlH}_{4}$ into functionalized scaffolds}

Preparation of nanoconfined $\mathrm{LiAlH}_{4}$ samples inside pores of carbon-based scaffolds was achieved via solution infiltration of $\mathrm{LiAlH}_{4}$ freshly recrystallized from diethylether. Prior to the infiltration, the mesoporous scaffolds CMK-3 and NCMK-3 were thermally treated at $350-380^{\circ} \mathrm{C}$ under a reducing $\mathrm{H}_{2}$ environment. The hydride nanocomposites are referred to as $\mathrm{LiAlH}_{4} @ \mathrm{CMK}-3$ and $\mathrm{LiAlH}_{4} @ N C M K-3$ depending on the scaffold type (Fig. 1a). $\mathrm{LiAlH}_{4}$ was mixed with the appropriate amount of the chosen scaffold in order to achieve a loading of $20 \mathrm{wt} \%$ in the final nanocomposite. This loading ensures an efficient and homogenous infiltration of the hydride inside the pores with minimum pore blockage.

The successful incorporation of $\mathrm{LiAlH}_{4}$ into the pores of CMK-3 and NCMK-3 was confirmed by several bulk and surface-sensitive characterization techniques. First, $\mathrm{N}_{2}$ isotherms at $77 \mathrm{~K}$ indicate a significant reduction in BET surface area and total pore volume upon nanoconfinement (Fig. 1C). The shape of the isotherms of the mesoporous carbons and their corresponding $\mathrm{LiAlH}_{4}$ loaded composites resemble a type IV(a) isotherm, featuring capillary condensation. ${ }^{30}$ Calculated pore size distributions reveal $5-6 \mathrm{~nm}$ mesopores in all samples (Fig. S1). Both NCMK-3 and LiAlH 4 @NCMK-3 exhibit a wider pore size distribution than CMK-3, consistent with the higher density of defect sites. $\mathrm{LiAlH}_{4}$ infiltration leads to a reduction of up to $50 \%$ in the BET surface area and the total volume for both CMK-3 and NCMK-3 samples (Table S1). FTIR spectroscopic measurements also indicate the presence of characteristic alanate Al-H stretching and bending modes in $\mathrm{LiAlH}_{4} @ \mathrm{CMK}-3$ and $\mathrm{LiAlH}_{4} @ \mathrm{NCMK}-3$. In addition, the FTIR 
spectra confirm that a significant fraction of $-\mathrm{OH}$ functional groups, which could possibly react with $\mathrm{LiAlH}_{4}$, are removed by $\mathrm{H}_{2}$ cycling treatment prior to infiltration (Fig. S2).

Powder X-ray diffraction (PXRD) results also support the nanoconfinement of $\mathrm{LiAlH}_{4}$ in these carbonbased composites. Both as-synthesized composites show only broad or low intensity reflections of $\mathrm{LiAlH}_{4}$ when compared to a simple physical mixture of NCMK-3 with an equivalent amount of $\mathrm{LiAlH}_{4}$, implying that $\mathrm{LiAlH}_{4}$ confined inside nanoporous hosts exists as nano-sized crystallites or as an amorphous phase (Fig. S3a). ${ }^{31}$ The as-synthesized $\mathrm{LiAlH}_{4} @ N C M K-3$ sample exhibits reflections of metallic Al peaks, indicating a partial decomposition of $\mathrm{LiAlH}_{4}$ during infiltration (Fig. 1d). Interestingly, ${ }^{7} \mathrm{Li}$ MAS NMR reveals that such decomposition generates $\mathrm{LiH}$ rather than the expected stable intermediate $\mathrm{Li}_{3} \mathrm{AlH}_{6}(\mathrm{Fig}$. S4). Surface-sensitive X-ray photoelectron spectroscopy (XPS) measurements provide clear evidence that four distinct $\mathrm{N}$ functionalities are present in NCMK-3 (Fig. S5 and Table S2). Pyridinic N and graphitic $\mathrm{N}$ are the major configurations on the surface of the NCMK-3, with minor contributions from oxidized and pyrrolic $\mathrm{N}$ groups. Interestingly, the high population of pyridinic nitrogen sites with electron-donating ability is preserved after hydride infiltration (Table $S 2$ and Supplementary note 1).

HAADF-STEM (high-angle annular dark field-scanning transmission electron microscopy) measurements on nanoconfined samples provide clear evidence of partial decomposition of $\mathrm{LiAlH}_{4}$ upon infiltration (Fig. 1b). In addition, a deposit of small $\sim 1 \mathrm{~nm}$ particles was observed on the carbon rods, presumably consisting of $\mathrm{LiAlH}_{4}$. There is a visible structure on the carbon walls in the inset of the infiltrated NCMK-3 shown in Fig $1 \mathrm{~b}$. This same surface structure is not observed in the non-infiltrated host material, and is thus assigned to the presence of $\sim 1 \mathrm{~nm} \mathrm{LiAlH}_{4}$ particles (Fig. S6a). The HAADF-STEM line profile of $\mathrm{LiAlH}_{4} @ \mathrm{NCMK}-3$ shows the Al signal is uniformly distributed throughout the $\mathrm{C}, \mathrm{N}, \mathrm{O}$ signals of NCMK-3, and supports a morphology of $\mathrm{LiAlH}_{4}$ uniformly coating the 1D rods of the NCMK-3 host, rather than filling the entire available pore space (Fig. S6b). Metallic Al nanoparticles with sizes between $~ 50-100 \mathrm{~nm}$ are formed outside the carbon pores, as evidenced from TEM images. The metallic character of Al was confirmed by harmonic peaks from EELS (electron energy loss spectroscopy), indicating a partial decomposition of $\mathrm{LiAlH}_{4}$ upon infiltration (Fig. S7). Interestingly, replacing diethylether with THF as a solvent for $\mathrm{LiAlH}_{4}$ infiltration still induces a partial decomposition of metastable $\mathrm{LiAlH}_{4}$ (Supplementary note 2 and Fig. S3b). This is consistent with our preliminary AIMD (ab initio molecular dynamics) calculations which indicate a strong interaction between the $\mathrm{N}$ binding sites and $\mathrm{LiAlH}_{4}$, leading to hydride decomposition and spontaneous formation of Li adatoms (vide infra) (Fig. S8).

\section{Hydrogen desorption and absorption}

Hydrogen desorption profiles were obtained using the volumetric Sieverts technique, and show a lower onset of $\mathrm{H}_{2}$ desorption temperature for $\mathrm{LiAlH}_{4} @ \mathrm{NCMK}-3$ compared to $\mathrm{LiAlH}_{4} @ \mathrm{CMK}-3$, implying that the Nfunctionalities can promote the decomposition of $\mathrm{LiAlH}_{4}$ (Fig. 2a). In accordance with the observed selfdecomposition of metastable $\mathrm{LiAlH}_{4}$ into $\mathrm{LiH}$ and Al in NCMK-3, the capacity of as-synthesized 
LiAlH $4 @$ @NMK-3 is slightly lower than that of $\mathrm{LiAlH}_{4} @ \mathrm{CMK}-3$. The onset dehydrogenation temperature in $\mathrm{LiAlH}_{4} @ \mathrm{NCMK}-3$ is as low as $126{ }^{\circ} \mathrm{C}, 45^{\circ} \mathrm{C}$ lower than in LiAlH ${ }_{4} @ \mathrm{CMK}-3$. Interestingly, the dehydrogenation of the $\mathrm{LiAlH}_{4} @ N C M K-3$ exhibits distinct double steps of hydrogen release with a short transition in the middle of the desorption step at around $157^{\circ} \mathrm{C}$. The origin of the double step is likely associated with various kinetic regimes for $\mathrm{LiAlH}_{4}$ decomposition inside functionalized NCMK-3 pores.

In-situ small angle X-ray scattering (SAXS) with simultaneous wide angle scattering (WAXS) $\mathrm{H}_{2}$ desorption experiments were used to probe the structural changes of nanoconfined $\mathrm{LiAlH}_{4}$ function of temperature (20 to $300{ }^{\circ} \mathrm{C}$ ) (Fig. 2b-e). These experiments indicate significant structural changes upon heating and formation of distinct metallic Al peaks. Interestingly, the in-situ WAXS only exhibits the decomposition of $\mathrm{LiAlH}_{4}$ to $\mathrm{LiH} / \mathrm{Al}$ without any indications of the stable intermediate phase $\mathrm{Li}_{3} \mathrm{AlH}_{6}$ upon heating. The intensity in the low-q region of $\mathrm{LiAlH}_{4} @ \mathrm{CMK}-3$ exhibits an increase at $75^{\circ} \mathrm{C}$ and higher, with a simultaneous decrease in peak area for the three mesostructure peaks (Fig. 2b). In contrast, $\mathrm{LiAlH}_{4} @$ NCMK-3 displays essentially no change in the small angle intensity (Fig. 2c). At $75^{\circ} \mathrm{C}$ and above, where the low-q SAXS intensity of $\mathrm{LiAlH}_{4} @ \mathrm{CMK}-3$ begins to increase, the WAXS patterns of both $\mathrm{LiAlH}_{4} @ \mathrm{CMK}-3$ and LiAlH ${ }_{4} @ N C M K-3$ show the decay of $\mathrm{LiAlH}_{4}$ and the formation of Al metal (Fig. 2d-e).

The reversible uptake of hydrogen in $\mathrm{LiAlH}_{4} @$ NCMK-3 was achieved by treating the dehydrogenated material under $100 \mathrm{MPa} \mathrm{H}_{2}$ pressure. The PXRD and MAS NMR results support the notion that $\mathrm{LiAlH}_{4} @ \mathrm{NCMK}-3$ shows unprecedented reversibility under $100 \mathrm{MPa}_{2}$ pressure at $50^{\circ} \mathrm{C}$, whereas the $\mathrm{LiAlH}_{4} @ \mathrm{CMK}-3$ composite cannot be rehydrogenated under those conditions. ${ }^{29}$ Prior studies have shown that nanoconfinement is as a viable approach to improve the hydrogen storage properties of $\mathrm{LiAlH}_{4}$; however, full reversibility has not been demonstrated. ${ }^{32-35} \mathrm{Fig}$. 3a displays the PXRD patterns of desorbed and rehydrogenated samples for $\mathrm{LiAlH}_{4} @ \mathrm{CMK}-3$ and $\mathrm{LiAlH}_{4} @ N C M K-3$. The evolution of metallic Al is observed in both $\mathrm{N}$-functionalized and non-functionalized samples, with no other crystalline byproducts formed during the decomposition. However, a prominent difference is observed in the rehydrogenated samples. In contrast to LiAlH ${ }_{4} @ C M K-3$, the N-functionalized LiAlH ${ }_{4} @ N C M K-3$ shows broad reflections of $\mathrm{LiAlH}_{4}$ after the rehydrogenation, as well as some residual Al metal peaks, demonstrating reversible formation of $\mathrm{LiAlH}_{4}$ from $\mathrm{LiH}$ and $\mathrm{Al}$ under high hydrogen pressure.

The most conclusive evidence for the reversible $\mathrm{H}_{2}$ uptake and release from $\mathrm{LiAlH}_{4} @ N C M K-3$ was obtained from MAS NMR, a technique which provides information about all species present in the sample, including the amorphous ones. Typical ${ }^{27} \mathrm{Al}$ MAS NMR peaks for the tetrahedral Al in $\mathrm{LiAlH}_{4}$ are observed at 98 ppm in both as-synthesized LiAlH ${ }_{4} @ N C M K-3$ and LiAlH ${ }_{4} @ C M K-3$ indicating successful hydride incorporation (Fig. 3c-e). ${ }^{36}$ After $\mathrm{H}_{2}$ desorption, Al peaks from four-coordinated $\mathrm{LiAlH}_{4}$ (and the remaining six-coordinated $\mathrm{Li}_{3} \mathrm{AlH}_{6}$ ) disappear in both samples, indicating complete decomposition into $\mathrm{LiH}$ and metallic Al. Upon rehydrogenation, the $\mathrm{LiAlH}_{4}$ peak at 98 ppm is only observed in $\mathrm{LiAlH}_{4} @ \mathrm{NCMK}-$ 3 , which confirms that the rehydrogenation reaction only occurs in $\mathrm{LiAlH}_{4} @ \mathrm{NCMK}-3$, in agreement with 
the PXRD results. These results confirm that metallic Al is the only Al-containing decomposition product upon desorption (Fig. 3b) since peaks for the intermetallic LiAl decomposition products that occur at 380 and $176 \mathrm{ppm}$ are not detected. The corresponding ${ }^{7} \mathrm{Li}$ NMR data (Fig. S9) also indicate that the regeneration proceeds from $\mathrm{LiH}$ to $\mathrm{LiAlH}_{4}$ without any indications of $\mathrm{Li}_{3} \mathrm{AlH}_{6}$ or intermetallic $\mathrm{LiAl}$ phases. Encouragingly, the integration of the ${ }^{27} \mathrm{Al}$ MAS NMR peaks reveals that during rehydrogenation $~ 80 \%$ of the initially infiltrated $\mathrm{LiAlH}_{4}$ is regenerated. In contrast, the ${ }^{27} \mathrm{Al}$ and ${ }^{7} \mathrm{Li} \mathrm{MAS} \mathrm{NMR} \mathrm{results} \mathrm{for} \mathrm{the}$ $\mathrm{LiAlH}_{4} @ \mathrm{CMK}-3$ samples reveal the same reaction products $(\mathrm{LiH}$ and $\mathrm{Al})$ and impurity peaks $\left(\mathrm{Al}_{2} \mathrm{O}_{3}\right)$, but the $\mathrm{LiAlH}_{4}$ peak is absent after rehydrogenation, confirming the reaction is only reversible when using the NCMK-3 scaffold.

HAADF-STEM images of the rehydrogenated composite show small Al species inside the NCMK-3 scaffold, in addition to the large metallic Al particles. Fig. 3b shows HAADF-STEM images and energy dispersive X-ray spectra (EDS) of the rehydrogenated $\mathrm{LiAlH}_{4} @ N C M K-3$. As expected from the PXRD patterns, the large 50-100 nm Al particles are detected outside the pores of the NCMK-3 scaffold. Both Alrich areas (at the Al particles), and other low-concentration Al areas were investigated for comparison, and the Al EDS signal was also detected from the background area, implying that species other than metallic Al exist inside the pores (Fig. S10), consistent with the ${ }^{27} \mathrm{Al}$ and ${ }^{7} \mathrm{Li}$ MAS NMR results.

\section{Origin of reversibility and altered reaction pathway}

Collectively, the experiments suggest three potentially governing physical effects: (1) nanoconfinement of $\mathrm{LiAlH}_{4}$ in CMK-3 and NCMK-3 destabilizes the $\mathrm{Li}_{3} \mathrm{AlH}_{6}$ intermediate upon $\mathrm{H}_{2}$ release; (2) Li adatoms form on nitrogen binding sites in NCMK-3 upon infiltration and affect the subsequent chemical reactivity of $\mathrm{LiAlH}_{4}$; and (3) both factors contribute to reversible $\mathrm{LiAlH}_{4}$ regeneration in NCMK-3 upon applying hydrogen pressure. Each of these effects was explored further using carefully controlled ab initio simulations, which confirm the experimental observations and offer additional insights into the origins of the observed behavior.

To explore the effect of confinement on the destabilization of $\mathrm{Li}_{3} \mathrm{AlH}_{6}$, we generated cluster models with varying sizes to evaluate the stability of all relevant compounds for each size. AIMD of $\mathrm{LiH}, \mathrm{Al}, \mathrm{Li}_{3} \mathrm{AlH}_{6}$ and $\mathrm{LiAlH}_{4}$ nanoclusters ranging from one to eight formula units were run, with the larger sizes approximating the real dimensions of the nanoconfined system (Fig. S11). As shown in the equilibrium structure in the inset of Fig. 4 a, the $\mathrm{AlH}_{6}{ }^{3-}$ units that are the building blocks of bulk $\mathrm{Li}_{3} \mathrm{AlH}_{6}$ become intrinsically unstable at the nanoscale, converting instead into $\mathrm{AlH}_{4}{ }^{-}$units. In contrast, the other tested species at the nanoscale retain their general molecular structure. A closer examination of the integrated radial atomic distributions reveals that the $\mathrm{Li}_{3} \mathrm{AlH}_{6}$ clusters of various sizes ( 1 to 8 formula units) consists of $\mathrm{AlH}_{4}{ }^{-}$units segregated on the surface and a core comprised of an atomic-scale mixture of $\mathrm{LiH}$ and $\mathrm{Al}$ (Fig. 4a). Spontaneous atomic-scale mixing of $\mathrm{LiH}$ and $\mathrm{Al}$ was further confirmed by complementary simulations of individual clusters in close proximity (Fig. S12). 
The $\mathrm{Li}_{3} \mathrm{AlH}_{6}$ destabilization at the nanoscale could be a response to the breakdown of intermolecular cohesion. To probe this, we computed the formation energy of each compound cluster from an assembly of individual molecular formula units (i.e., cluster size of unity). As shown in Fig. 4b, much larger clusters of $\mathrm{Li}_{3} \mathrm{AlH}_{6}$ are required to recover the stabilizing effect of bulk cohesion compared to the other reaction compounds. We can therefore conclude that the $\mathrm{Li}_{3} \mathrm{AlH}_{6}$ phase is significantly destabilized upon nanosizing, consistent with the lack of any indication of $\mathrm{Li}_{3} \mathrm{AlH}_{6}$ in experimental data. Instead, the system bypasses $\mathrm{Li}_{3} \mathrm{AlH}_{6}$, and hydrogenation and dehydrogenation cycles only involve $\mathrm{LiAlH}_{4}$ and $\mathrm{LiH}$ phases.

This inhibition of the $\mathrm{Li}_{3} \mathrm{AlH}_{6}$ phase is an important key for understanding the hydrogen release from $\mathrm{LiAlH}_{4} @ N C M K-3$. We conclude that the two-step decomposition of $\mathrm{LiAlH}_{4}$ is attributable to hydrogen release from nanoconfined $\mathrm{LiAlH}_{4}$ in various chemical environments inside pores of NCMK-3. The overall process can be represented as $\mathrm{LiAlH}_{4} \rightarrow \mathrm{LiH}+\mathrm{Al}+3 / 2 \mathrm{H}_{2}$ based on the following observations. Unlike other observed desorption profiles which show gradually increasing desorption rate, the first decomposition step of $\mathrm{LiAlH}_{4} @ \mathrm{NCMK}-3$ displays fast linear desorption, indicating hydrogen release from $\mathrm{LiAlH}_{4}$ nanoparticles (Fig. 2a). In addition, we rule out the possibility that the second release is the decomposition of $\mathrm{Li}_{3} \mathrm{AlH}_{6}$ because there are no indications of a stable intermediate $\mathrm{Li}_{3} \mathrm{AlH}_{6}$ phase, including the highly sensitive ${ }^{27} \mathrm{Al}$ MAS NMR technique. This confirms the prediction that the $\mathrm{H}_{2}$ desorption of $\mathrm{LiAlH}_{4}$ nanoparticles in $\mathrm{LiAlH}_{4} @ N C M K-3$ bypasses the stable $\mathrm{Li}_{3} \mathrm{AlH}_{6}$ phase. Notably, this is similar to the observed decomposition behavior of $\mathrm{NaAlH}_{4}$ at nanoscale. ${ }^{31,37}$

Another factor potentially in play is the nature of the interaction between $\mathrm{LiAlH}_{4}$ and carbon scaffolds. We ran additional AIMD simulations of $\mathrm{LiAlH}_{4}$ clusters on planar pristine graphene and pyridinic $\mathrm{N}$-doped graphene sheets to approximate scaffold walls in CMK-3 and NCMK-3 (Fig. S13). Although there is evidence for graphitic and pyrrolic defects in the scaffold (Fig. S1), we focused on the pyridinic defects to explore the interaction with $\mathrm{LiAlH}_{4}$ since the higher degree of excess charge localization on pyridinic defects is likely to have a greater overall impact on the reaction. On pristine graphene (broadly representative of CMK-3), the AIMD simulations reveal little change in the structure of the $\mathrm{LiAlH}_{4}$ cluster. However, in the presence of the pyridinic $\mathrm{N}$ defect, Li atoms are drawn away from the cluster towards the graphene surface to coordinate with $\mathrm{N}$. Using $\mathrm{Li}$ energy references derived from bulk state $\mathrm{LiAlH}_{4}, \mathrm{LiH}, \mathrm{Al}$ and gaseous $\mathrm{H}_{2}$, it is determined that the Li coordination reaction is exergonic and thus irreversible after initial infiltration (Fig. S13). This coordination also anchors the cluster to the surface, suggesting a strong interaction and indicating an impact well beyond the single Li adatom involved in the Li-N bond formation (Fig. 4c-d).

To further investigate the nature of the Li-N interaction, we analyzed the electronic structure of pristine graphene and pyridinic $\mathrm{N}$-doped graphene models in the presence of the $\left(\mathrm{LiAlH}_{4}\right)_{6}$ clusters (Fig. $\left.4 \mathrm{e}\right)$. On pristine graphene, the addition of $\mathrm{LiAlH}_{4}$ has little effect on the electronic density of states (DOS). On the other hand, if pyridinic $\mathrm{N}$ is present, the localized state associated with the $\mathrm{N}$ atom exhibits a pronounced chemical change upon incorporation of $\mathrm{LiAlH}_{4}$, delocalizing its charge. This different behavior of the two 
model carbon hosts can be rationalized in part based on the low DOS of graphitic derivatives in the vicinity of the Fermi level, which requires a large energetic penalty for charge redistribution. The presence of pyridinic $\mathrm{N}$ removes this DOS limitation, permitting the host to take a more direct role in the process. The positive impact of $\mathrm{N}$ on the otherwise low graphitic DOS has been invoked to rationalize improved kinetics in other carbon-confined hydrogen storage materials, ${ }^{24}$ and closely parallels the known role of $\mathrm{N}$ in overcoming DOS limitations in carbon materials for electrochemical energy storage. ${ }^{38}$

Notably, the dominant effect of $\mathrm{LiAlH}_{4}$ incorporation on the DOS of $\mathrm{N}$-doped graphene is well captured by the simple approximation of single adsorbed Li atom on that surface (Fig. S14). This confirms that the Li$\mathrm{N}$ interaction dominates the essential physics, and that Li atoms are indeed drawn away from the primary cluster (see Fig. S14 for a corresponding map of the charge density redistribution). Using this simple Liadsorbed model, we were also able to reproduce an observed shift in the experimentally measured X-ray absorption spectrum (XAS) of N K-edge in neat NCMK-3, as-synthesized, desorbed, and rehydrogenated $\mathrm{LiAlH}_{4} @$ NCMK-3. As shown in Fig. S15, the predicted Li-N chemical interaction leads to an energy shift in the computed XAS results that is quantitatively consistent with the measured spectra. This same XAS energy shift is detected under all measured conditions, supporting the conclusion that Li-N coordination is an irreversible process and confirming that $\mathrm{Li}$ adatoms near pyridinic $\mathrm{N}$ defects introduced during infiltration remain bound in the following (de)hydrogenation cycles.

The retention of $\mathrm{Li}$ at the $\mathrm{N}$ sites is expected to further impact the reaction cycle, including reversibility. To explore this effect further, a new set of models containing one Li atom anchored to each $\mathrm{N}$ site was generated, with additional $(\mathrm{LiH}+\mathrm{Al})_{6}$ and $\left(\mathrm{LiAlH}_{4}\right)_{6}$ incorporated separately as the reactant and product, respectively. From Fig. $4 \mathrm{f}$, the presence of the anchored Li adatoms on the $\mathrm{N}$ sites significantly alters the structural configurations of the clusters, enhancing spreading along the surface to maximize the Li-N interactions. Based on these models, the thermodynamic impact was assessed. Note that with the small cluster sizes accessible within our model (chosen to facilitate manageable structural sampling while capturing the essential effect of cohesive interactions on phase stability), all computed $\Delta \mathrm{E}_{\text {hydriding }}$ are exothermic regardless of the presence or nature of hosts. However, a more meaningful comparison can be obtained by instead examining the effect on the hydriding reaction energy, $\Delta \mathrm{E}_{\text {hydriding, }}$, for a given cluster size. For the $(\mathrm{LiH}+\mathrm{Al})_{6}$ to $\left(\mathrm{LiAlH}_{4}\right)_{6}$ conversion under $\mathrm{H}_{2}$, the presence of $\mathrm{Li}$ adatoms on $\mathrm{N}$ defect sites lowers $\Delta \mathrm{E}_{\text {hydriding }}$ by $8 \mathrm{~kJ} \mathrm{~mol}^{-1} \mathrm{H}_{2}$ compared to pristine graphene (Fig. 4f), and by $4 \mathrm{~kJ} \mathrm{~mol}^{-1} \mathrm{H}_{2}$ compared to unsupported clusters in vacuo. This trend should also hold for larger cluster sizes, implying that $\mathrm{H}_{2}$ uptake is more energetically favorable in the presence of $\mathrm{N}$ dopants. Notably, this is consistent with the observed difference in hydriding behavior between the CMK-3 and NCMK-3 confined materials, confirming the role of the $\mathrm{Li}$ adatom formation on $\mathrm{N}$ binding sites and resulting charge redistribution on reaction thermodynamics.

Conclusion and outlook. We demonstrate here a conceptually new strategy for altering the reaction pathways and energetics of chemical processes at nanoscale. The thermodynamic properties of metastable $\mathrm{LiAlH}_{4}$ are significantly modified by confinement in nanochannels of $\mathrm{N}$-doped CMK-3. Our 
experiments and calculations reveal that the N-functionalities on the NCMK-3 scaffold promote lowtemperature dehydrogenation of $\mathrm{LiAlH}_{4}$ to form Al particles and $\mathrm{LiH}$, bypassing the stable $\mathrm{Li}_{3} \mathrm{AlH}_{6}$ intermediate phase observed in bulk. Remarkably, the material obtained after hydrogen desorption from $\mathrm{LiAlH}_{4} @ N$ NCMK-3 can be regenerated back into $\mathrm{LiAlH}_{4}$ in $80 \%$ yield, which has thus far been regarded as not feasible. DFT and AIMD modelling results indicate that the contribution of cluster cohesion energy is far weaker for $\left(\mathrm{Li}_{3} \mathrm{AlH}_{6}\right)_{n}$ than for $\left(\mathrm{LiAlH}_{4}\right)_{n}$ clusters $(\mathrm{n}=1-8)$, leading to the bypassing of the intermediate $\mathrm{Li}_{3} \mathrm{AlH}_{6}$ phase. Furthermore, it was revealed that $\mathrm{N}$ defect sites can lower the energy of hydriding $\left(\Delta \mathrm{E}_{\text {hydriding }}\right)$ by interacting with $\mathrm{LiAlH}_{4}$ clusters more intimately than in pristine carbon, changing the DOS in the vicinity of the Fermi level and effectively acting as solvation sites for lithium ions.

Strict control over the orientation of hydrides at the nanoscale can enable precise placement of electron acceptor species in the vicinity of electron donor species within the porous host to optimize the promotional effects observed, accelerate the $\mathrm{H}_{2}$ sorption kinetics, and tune the energetics of chemical reactions. As the results in this work indicate, the creation of such a "designed metal hydridefunctionalized scaffold composite" and the optimal tuning of its properties can address important materials science challenges in energy generation and storage and can lead to a better understanding of confinement effects in nanoscale volumes. ${ }^{39}$

\section{Methods}

\section{Purification of Lithium Aluminum Hydride $\left(\mathrm{LiAlH}_{4}\right)$}

$\mathrm{LiAlH}_{4}$ was purified by recrystallization prior to use by dissolving $2.0 \mathrm{~g}$ of commercial $\mathrm{LiAlH}_{4}(\mathrm{Sigma}$ Aldrich) in $25 \mathrm{~mL}$ of diethyl ether, followed by filtration via a $0.45 \mu \mathrm{m}$ PTFE syringe filter. The clear, filtered solution was recrystallized and vacuum dried overnight in a Schlenk flask, and a fine white powder of $\mathrm{LiAlH}_{4}$ was obtained. All purification steps were conducted under an inert Ar atmosphere $\left(<0.2 \mathrm{ppm} \mathrm{O_{2 }}\right.$ and $\mathrm{H}_{2} \mathrm{O}$ ).

\section{Treatment of carbon materials under hydrogen}

Mesoporous carbons CMK-3 and N-doped CMK-3 (NCMK-3, 21 wt\% nitrogen) were purchased from ACS Materials Inc. and pretreated in a reducing hydrogen environment at elevated temperatures to remove oxygen containing surface functionalities and trapped water molecules within the pores, which can potentially react with $\mathrm{LiAlH}_{4}$. The pretreatment was performed in the hydrogen cycling kinetics measurement mode of a PCT-Pro Sieverts type apparatus at temperatures between 350 and $380{ }^{\circ} \mathrm{C}$. Each hydrogen cycle consists of three steps: $60 \mathrm{~min}$ at 20 bar H$_{2}, 5$ min under static vacuum, and 10 min under dynamic vacuum to remove volatiles. The carbon materials were treated for at least 10 cycles and subsequently transferred into an Ar glovebox for the solvent-driven infiltration. 
$25 \mathrm{mg}$ of purified $\mathrm{LiAlH}_{4}$ was dissolved into $1.25 \mathrm{~mL}$ of dried diethyl ether obtained from a solvent purification system. The $\mathrm{LiAlH}_{4}$ solution was filtrated by $0.45 \mu \mathrm{m}$ syringe filter and added to $100 \mathrm{mg}$ of the pretreated mesoporous carbon scaffolds (CMK-3 and NCMK-3). The mixture was kept at or slightly below $-50^{\circ} \mathrm{C}$ for 1 hour and evacuated at room temperature for 4 hours. Finally, the evacuated samples were heated to $50^{\circ} \mathrm{C}$ for 2 hours to remove residual solvent in an Ar glovebox.

\section{Hydrogen uptake and release}

$\mathrm{H}_{2}$ desorption: The desorption of the nanoconfined $\mathrm{LiAlH}_{4}$ samples was conducted with a Sievert-type apparatus (PCTPro, Setaram). The samples were heated at a ramp rate of $2{ }^{\circ} \mathrm{C} \mathrm{min}^{-1}$ from room temperature to $240^{\circ} \mathrm{C}$ and maintained at $240{ }^{\circ} \mathrm{C}$ for 4 hours. The desorbed powder samples were collected under an Ar atmosphere. High-pressure hydrogenation: The desorbed samples were hydrogenated in a custom high-pressure system, capable of reaching $100 \mathrm{MPa}$ via a Newport Scientific compressor. The high-pressure vessel (Hi-Pressure 316 SS) was assembled and loaded in an Arcontaining glovebox. First, samples were loaded into stainless steel crucibles capped with frits. Up to four crucibles were then loaded into the vessel along with cylindrical stainless steel slugs to ensure the samples all rest in the main heating zone of the furnace. The closed vessel was then transported to the high-pressure system, where all gas lines were purged three times with helium prior to opening the vessel. The vessel was purged an additional three times each with helium and hydrogen. For tests at $100 \mathrm{MPa}$ and $50{ }^{\circ} \mathrm{C}$, the system was first pressurized to $90 \mathrm{MPa}$ with hydrogen to avoid over-pressurization upon heating. The vessel was then heated to $50^{\circ} \mathrm{C}$ and the pressure was regularly monitored and topped off as needed to maintain the desired $100 \mathrm{MPa}$ set point. The vessels were held isothermal and isobaric for 1-3 days, after which time the system was cooled to room temperature before venting the pressure. The vessel was closed and returned to the Ar glovebox for disassembly and sample collection.

\section{Characterization}

Powder X-ray diffraction patterns were acquired on an Oxford Diffraction Supernova in capillary mode (Cu Ka radiation) using a CCD detector at $77 \mathrm{~mm}$ from the samples with an exposure time of $60 \mathrm{~s}$. The recorded 2D images were added and integrated to generate a 1D pattern. The samples were packed into $0.7 \mathrm{~mm}$ diameter capillaries inside a glovebox and sealed with vacuum grease. Infrared spectra were collected inside of a Ar glove-box on an Agilent Technologies Cary-630 instrument equipped with an attenuated total reflectance unit. Before each measurement, a background spectrum was collected. Nitrogen physisorption isotherms were measured on a Quantachrome Autosorb iQ instrument at $77 \mathrm{~K}$ using a $\mathrm{N}_{2}$ bath for cooling. Prior to each measurement, the sample is degassed in vacuum for at least 6 hours. All gases used for the measurements were $99.999 \%$ purity or higher. The BET specific surface areas were obtained from the $\mathrm{N}_{2}$ absorption isotherms in a relative pressure range of 0.05 to 0.2 . Pore size distributions were derived using the density functional theory calculation fitting of adsorption curves with QSDFT cylinder/slit pore equilibrium kernel. X-ray photoelectron spectroscopy (XPS) data were collected using an Omicron DAR400 X-ray source and Physical Electronics 10-360 electron-energy. The Xray source was an $\mathrm{Al}$ anode $(\mathrm{PE}=1486.6 \mathrm{eV})$ and the pass energy of the analyzer was $23.5 \mathrm{eV}$. Analysis 
of XPS spectra was performed using the CasaXPS software. Spectra were calibrated to the adventitious $C$ 1 s peak at $285 \mathrm{eV}$. SAXS/WAXS measurements were conducted at SSRL beam line 1-5 with $\lambda=0.7999 \AA$ incident energy and a $1 \mathrm{~m}$ sample-to-detector distance. Samples were prepared in $\varnothing 1.0 \mathrm{~mm}$ quartz capillaries with $10 \mu \mathrm{m}$ thick walls in an Ar glovebox and connected to a heating cell ${ }^{40}$ with Swagelok compression fittings. A type $\mathrm{K}$ thermocouple was inserted into the capillary to monitor sample temperature. The sample cell transferred from the glovebox air-free was interfaced to a gas handling manifold where the samples were evacuated and subsequently pressurized with 4 bar $\mathrm{H}_{2}$ backpressure for all measurements. 2D SAXS and WAXS images were processed and radially integrated with the Nika macro $^{41}$ in IgorPro.

High-angle annular dark-field (HAADF) scanning transmission electron microscopy (STEM) images and EDX line scans shown in Fig. 1b and Fig. S6: the powder of $\mathrm{LiAlH}_{4} @ N C M K-3$ was diluted in dry toluene and a drop of sample solution was placed onto a lacey carbon TEM grid, which was dried under vacuum overnight. The image shown in the left panel of the Fig. $\mathbf{1 b}$ is obtained on a JEOL JEM-2100F microscope operated at $200 \mathrm{kV}$, and the image shown in the right panel of the Fig. 1b is obtained on a JEOL ARM200F aberration-corrected microscope operated at $80 \mathrm{kV}$ and installed at National Center for Interuniversity Research Facility (South Korea). The samples were shortly exposed to air immediately before the sample loading. The convergence semi-angle is $19 \mathrm{mrad}$ and the collection semi-angle spans from 68 to 280 mrad. EDX line scan was performed on the ARM-200F microscope with an Oxford Instruments X-Max SDD with an active area of $100 \mathrm{~mm}$ and a solid angle of $0.9 \mathrm{sr}$. Transmission electron microscopy and energy dispersive X-ray spectroscopy elemental mapping in Fig. 3b, Fig. S7, and S10 were conducted on a ThermoFisher Titan Themis Z TEM operated at $300 \mathrm{kV}$. The samples were immersed in dry toluene and then dropcast onto $\mathrm{Cu}$ grids coated with a lacey carbon film. EDX data were collected with a Super-X four-quadrant silicon drift detector (SDD) with a collection solid angle of approximately $0.7 \mathrm{sr}$. Data were collected with pixel times of $10-20 \mu \mathrm{s}$, and multiple frames were collected with drift correction for total acquisition times of approximately $10 \mathrm{~min}$. Elemental maps were generated after parabolic background subtraction. $X$-ray absorption spectra were acquired at Beamline 8.0.1.4 at the Advanced Light Source. All samples were prepared in an Ar-filled glovebox $\left(\mathrm{H}_{2} \mathrm{O}, \mathrm{O}_{2}<0.1 \mathrm{ppm}\right)$ with an UHV compatible transfer tool, allowing the samples to be mounted in the experimental chamber without ever exposing them to air. XAS measurements were carried out under UHV conditions at less than $1.0 \times 10^{-}$ ${ }^{9}$ torr. XAS was conducted in surface-sensitive total electron yield mode and bulk sensitive fluorescence mode. Sieverts measurements were performed on a PCT-Pro2000 instrument (Setaram, Inc). Approximately $150 \mathrm{mg}$ of sample was transferred to the reactor connected to the instrument. Prior to each measurement, the reactor was evacuated, and the volume was calibrated using He gas. Magic Angle Spinning Nuclear Magnetic Resonance (MAS NMR) measurements were collected using a triple resonance probe on a $600 \mathrm{MHz}(14 \mathrm{~T}$ ) Bruker Biospin Avance III, operating at 156.37 and $233.24 \mathrm{MHz}$ for ${ }^{27} \mathrm{Al}$ and ${ }^{7} \mathrm{Li}$, respectively. Additional details on the specifics of MAS NMR measurements are provided in the SI (Supplementary note 3).

\section{Theoretical Calculations}


DFT calculations and ab initio molecular dynamics simulations were performed with the Vienna ab initio simulation package (VASP). NVT-ensemble ab initio molecular dynamics simulations were performed within the Born-Oppenheimer (BO) approximation with temperature regulated by the Nosé-Hoover thermostat. The N K-edge X-ray absorption (XAS) spectra are calculated using the quantum espresso source code package with the Shirley reduced basis for efficient Brillouin zone sampling. Standard PBEGGA approximation is used to estimate the exchange-correlation functional in DFT (additional details are shown in Supplementary note 4).

\section{Declarations}

\section{Author information}

\section{Corresponding authors}

Brandon C. Wood (wood37@llnl.gov); Eun Seon Cho (escho@kaist.ac.kr); Vitalie Stavila (vnstavi@sandia.gov).

\section{Data availability}

The datasets generated during the current study are available from the corresponding authors on request.

\section{Author contributions}

V.S., B.C.W. and E.S.C. conceived and coordinated the project. Y.C. performed the synthesis of nanoconfined materials with help from J.L.S. and A.S. M.A.T.W. and H.E.M. performed the solid-state NMR measurements. Y.C., V.S., F.E.G., J.L.S. and N.A.S. carried out the XRD, XAS, XPS and SAXS measurements. J.D.S., S.K., M.K., H.P. and J.P performed the TEM, EELS and EDS experiments. S.L., L.F.W. and B.C.W. performed the $a b$ initio simulations. Y.C., S.L, B.C.W, E.S.C., M.D.A. and V.S. wrote the manuscript and prepared the figures with help from the other co-authors. All the authors contributed to the scientific discussions, data analysis, and preparation of the manuscript.

\section{Acknowledgements}

Sandia National Laboratories is a multimission laboratory managed and operated by National Technology and Engineering Solutions of Sandia, LLC., a wholly owned subsidiary of Honeywell International, Inc., for the U.S. Department of Energy's National Nuclear Security Administration under contract DE-NA-0003525. The authors gratefully acknowledge funding from the U.S. Department of Energy, Office of Energy Efficiency and Renewable Energy, Hydrogen and Fuel Cell Technologies Office, through the Hydrogen Storage Materials Advanced Research Consortium (HyMARC). This work was supported by the International Energy Joint R\&D Program of the Korea Institute of Energy Technology Evaluation and Planning (KETEP), granted financial resource from the Ministry of Trade, Industry \& Energy, Republic of Korea (No. 20188520000570), and also by Energy Cloud R\&D Program through the National Research Foundation of Korea (NRF) funded by Ministry of Science, ICT (No. 
2019M3F2A1072234). The computational portion of the work was performed under the auspices of the DOE by Lawrence Livermore National Laboratory (LLNL) under Contract DE-AC52-07NA27344, with computing support from the LLNL Institutional Computing Grand Challenge program. This work was supported by the Laboratory Directed Research and Development (LDRD) program at Sandia National Laboratories. This research used resources from the Advanced Light Source, which is a DOE Office of Science User Facility under contract no. DE-AC02-05CH11231. Any subjective views or opinions that might be expressed in the paper do not necessarily represent the views of the U.S. Department of Energy or the United States Government.

\section{Competing interests}

The authors declare no competing interests.

\section{References}

1. Aykol, M., Dwaraknath, S. S., Sun, W. \& Persson, K. A. Thermodynamic limit for synthesis of metastable inorganic materials. Science Adv. 4, eaaq0148 (2018).

2. Ye, L. et al. Toward higher voltage solid-state batteries by metastability and kinetic stability design. Energy Mater. 10, 2001569 (2020).

3. Ratha, S. et al. Urea-assisted room temperature stabilized metastable $\beta$-NiMoO4: Experimental and theoretical insights into its unique bifunctional activity toward oxygen evolution and supercapacitor. ACS Appl. Mater. Interfaces 9, 9640-9653 (2017).

4. Tasnádi, F. et al. Origin of the anomalous piezoelectric response in wurtzite $\mathrm{Sc}_{x} \mathrm{Al}_{1-\mathrm{x}} \mathrm{N}$ alloys. Rev. Lett. 104, 137601 (2010).

5. Vidal, J., Lany, S., Francis, J., Kokenyesi, R. \& Tate, J. Structural and electronic modification of photovoltaic SnS by alloying. Appl. Phys. 115, 113507 (2014).

6. Zhang, Z., Zandkarimi, B. \& Alexandrova, A. N. Ensembles of metastable states govern heterogeneous catalysis on dynamic interfaces. Chem. Res. 53, 447-458 (2020).

7. Kumar, R., Karkamkar, A., Bowden, M. \& Autrey, T. Solid-state hydrogen rich boron-nitrogen compounds for energy storage. Soc. Rev. 48, 5350-5380 (2019).

8. Graetz, J., Wegrzyn, J. \& Reilly, J. J. Regeneration of lithium aluminum hydride. Am. Chem. Soc. 130, 17790-17794 (2008).

9. Zidan, R. et al. Aluminium hydride: a reversible material for hydrogen storage. Commun., 3717-3719 (2009).

10. Schüth, F., Bogdanović, B. \& Felderhoff, M. Light metal hydrides and complex hydrides for hydrogen storage. Commun., 2249-2258 (2004).

11. Ni, C., Yang, L., Muckerman, J. T. \& Graetz, J. N-Alkylpyrrolidine- alane compounds for energy applications. Phys. Chem. C117, 2628-2634 (2013). 
12. Lacina, D. et al. Investigation of $\mathrm{LiAlH}_{4}-\mathrm{THF}$ formation by direct hydrogenation of catalyzed $\mathrm{Al}$ and LiH. Chem. Chem. Phys. 14, 6569-6576 (2012).

13. Wang, J., Ebner, A. D. \& Ritter, J. A. Physiochemical pathway for cyclic dehydrogenation and rehydrogenation of $\mathrm{LiAlH}_{4}$. Am. Chem. Soc. 128, 5949-5954 (2006).

14. Wong, B. M., Lacina, D., Nielsen, I. M., Graetz, J. \& Allendorf, M. D. Thermochemistry of alane complexes for hydrogen storage: a theoretical and experimental investigation. Phys. Chem. C 115, 7778-7786 (2011).

15. Ni, C., Wegrzyn, J. E., Zhou, W., Celebi, Y. \& Graetz, J. N-alkylpiperidine-alane compounds and their applications in alane regeneration. J. Hydrogen Energy 38, 9779-9785 (2013).

16. Schneemann, A. et al. Nanostructured metal hydrides for hydrogen storage. Rev. 118, 10775-10839 (2018).

17. Nielsen, T. K., Besenbacher, F. \& Jensen, T. R. Nanoconfined hydrides for energy storage. Nanoscale 3, 2086-2098 (2011).

18. Jeon, K.-J. et al. Air-stable magnesium nanocomposites provide rapid and high-capacity hydrogen storage without using heavy-metal catalysts. Mater. 10, 286 (2011).

19. Chong, L., Zeng, X., Ding, W., Liu, D.-J. \& Zou, J. $\mathrm{NaBH}_{4}$ in “Graphene wrapper:" Significantly enhanced hydrogen storage capacity and regenerability through nanoencapsulation. Mater. 27, 5070-5074 (2015).

20. Cho, E. S. et al. Graphene oxide/metal nanocrystal multilaminates as the atomic limit for safe and selective hydrogen storage. Commun. 7, 10804 (2016).

21. Schneemann, A. et al. Nanoconfinement of molecular magnesium borohydride captured in a bipyridine-functionalized Metal-Organic Framework. ACS Nano 14, 10294-10304 (2020).

22. White, J. L. et al. Melting of magnesium borohydride under high hydrogen pressure: Thermodynamic stability and effects of nanoconfinement. Mater. 32, 5604-5615 (2020).

23. de Jongh, P. E., Allendorf, M., Vajo, J. J. \& Zlotea, C. Nanoconfined light metal hydrides for reversible hydrogen storage. MRS Bull. 38, 488-494 (2013).

24. Carr, C. L. et al. Anomalous $\mathrm{H}_{2}$ Desorption rate of $\mathrm{NaAlH}_{4}$ confined in nitrogen-doped nanoporous carbon frameworks. Mater. 30, 2930-2938 (2018).

25. Carr, C. L. \& Majzoub, E. H. Surface-functionalized nanoporous carbons for kinetically stabilized complex hydrides through Lewis acid-Lewis base chemistry. Phys. Chem. C120, 11426-11432 (2016).

26. Liu, X., McGrady, G. S., Langmi, H. W. \& Jensen, C. M. Facile cycling of Ti-doped $\mathrm{LiAlH}_{4}$ for high performance hydrogen storage. Am. Chem. Soc. 131, 5032-5033 (2009).

27. Liu, S. S. et al. Improved reversible hydrogen storage of $\mathrm{LiAlH}_{4}$ by nano-sized $\mathrm{TiH}_{2}$. J. Hydrogen Energy 38, 2770-2777 (2013).

28. Ares, J. R. et al. Thermal and mechanically activated decomposition of $\mathrm{LiAlH}_{4}$. Res. Bull. 43, 12631275 (2008). 
29. Ke, X. \& Chen, C. Thermodynamic functions and pressure-temperature phase diagram of lithium alanates by ab initio calculations. Rev. B 76, 024112 (2007).

30. Thommes, M. et al. Physisorption of gases, with special reference to the evaluation of surface area and pore size distribution (IUPAC Technical Report). Pure Appl. Chem. 87, 1051-1069 (2015).

31. Stavila, V., Bhakta, R. K., Alam, T. M., Majzoub, E. H. \& Allendorf, M. D. Reversible hydrogen storage by $\mathrm{NaAlH}_{4}$ confined within a titanium-functionalized MOF-74 (Mg) nanoreactor. ACS Nano 6, 98079817 (2012).

32. Wang, L., Rawal, A., Quadir, M. Z. \& Aguey-Zinsou, K. F. Nanoconfined lithium aluminium hydride $\left(\mathrm{LiAlH}_{4}\right)$ and hydrogen reversibility. J. Hydrogen Energy 42, 14144-14153 (2017).

33. Zhao, Y. R., Han, M., Wang, H. X., Chen, C. C. \& Chen, J. LiAlH ${ }_{4}$ supported on $\mathrm{TiO}_{2} /$ hierarchically porous carbon nanocomposites with enhanced hydrogen storage properties. Chem. Front. 3, 15361542 (2016).

34. Ngene, P., Verkuijlen, M. H. W., Barre, C., Kentgens, A. P. M. \& de Jongh, P. E. Reversible Li-insertion in nanoscaffolds: A promising strategy to alter the hydrogen sorption properties of Li-based complex hydrides. Nano Energy 22, 169-178 (2016).

35. Wahab, M. A. \& Beltramini, J. N. Catalytic nanoconfinement effect of in-situ synthesized Nicontaining mesoporous carbon scaffold (Ni-MCS) on the hydrogen storage properties of $\mathrm{LiAlH}_{4}$. J. Hydrogen Energy 39, 18280-18290 (2014).

36. Wiench, J., Balema, V., Pecharsky, V. \& Pruski, M. Solid-state ${ }^{27}$ AI NMR investigation of thermal decomposition of $\mathrm{LiAlH}_{4}$. Solid State Chem. 177, 648-653 (2004).

37. Bhakta, R.K. et al. A Thermodynamics and kinetics of $\mathrm{NaAlH}_{4}$ nanocluster decomposition. Chem. Chem. Phys. 14, 8160-8169 (2012).

38. Wood, B. C., Ogitsu, T., Otani, M. \& Biener, J. First-principles-inspired design strategies for graphenebased supercapacitor electrodes. Phys. Chem. C118, 4-15 (2014).

39. Meldrum, F. C. \& O'Shaughnessy, C. Crystallization in confinement. Mater. 32, 2001068 (2020).

40. Hoffman, A. S., Singh, J. A., Bent, S. F. \& Bare, S. R. In situ observation of phase changes of a silicasupported cobalt catalyst for the Fischer-Tropsch process by the development of a synchrotroncompatible in situ/operando powder X-ray diffraction cell. Synchrotron Rad. 25, 1673-1682 (2018).

41. Ilavsky, J. Nika: software for two-dimensional data reduction. Appl. Crystallogr. 45, 324-328 (2012).

42. Jun, S. et al. Synthesis of new, nanoporous carbon with hexagonally ordered mesostructure. Am. Chem. Soc. 122, 10712-10713 (2000).

43. Block, J. \& Gray, A. The thermal decomposition of lithium aluminum hydride. Chem. 4, 304-305 (1965).

\section{Table}


Table 1. Three thermal decomposition reaction steps of bulk $\mathrm{LiAlH}_{4}$ and their corresponding hydrogen storage capacities and reaction enthalpies. ${ }^{43}$

\begin{tabular}{|c|c|c|c|}
\hline Number & Reaction & $\begin{array}{l}\text { Hydrogen storage capacity } \\
\text { (wt. \%) }\end{array}$ & $\begin{array}{c}\Delta \mathrm{H} \\
\left(\mathrm{kJ} \mathrm{mol}^{-1} \mathrm{H}_{2}\right)\end{array}$ \\
\hline R1 & $3 \mathrm{LiAlH}_{4} \rightarrow \mathrm{Li}_{3} \mathrm{AlH}_{6}+2 \mathrm{Al}+3 \mathrm{H}_{2}$ & 5.3 & -10 \\
\hline R2 & $\mathrm{Li}_{3} \mathrm{AlH}_{6} \rightarrow 3 \mathrm{LiH}+\mathrm{Al}+3 / 2 \mathrm{H}_{2}$ & 2.6 & 25 \\
\hline R3 & $\mathrm{LiH}+\mathrm{Al} \rightarrow \mathrm{LiAl}+1 / 2 \mathrm{H}_{2}$ & 2.6 & - \\
\hline
\end{tabular}

Figures 

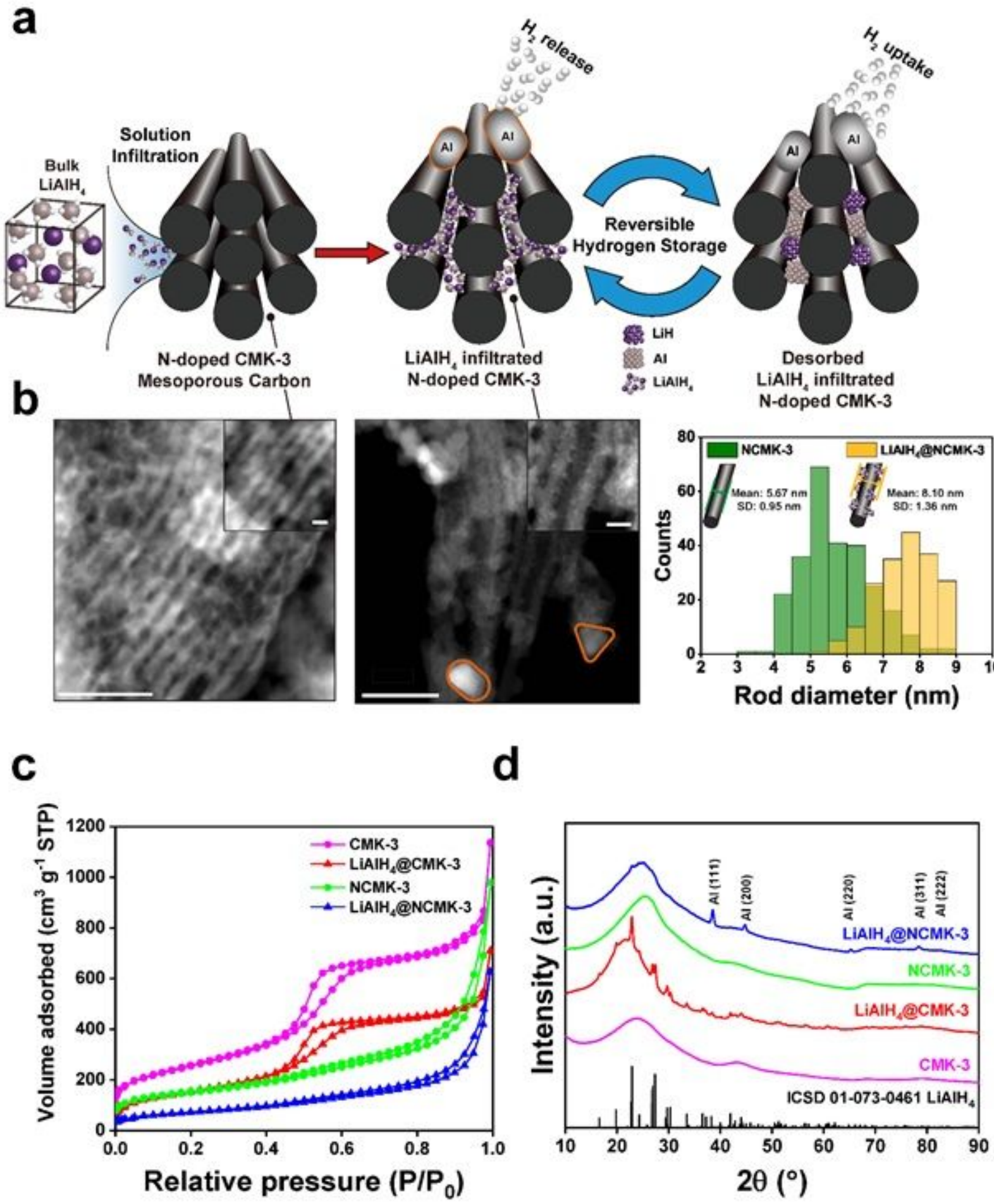

Figure 1

Hydrogen storage mechanism of nanoconfined LiAlH4 in N-doped mesoporous CMK-3 and its structure. a, Schematic representation of synthesis and hydrogen storage mechanism of nanoconfined LiAlH4 in the NCMK-3 scaffold. b, High-angle annular dark field scanning transmission electron microscopy (HAADF-STEM) image of N-doped CMK-3 (left), nanoconfined LiAlH4 in NCMK-3 (middle), and histograms of rod diameters in NCMK-3 and LiAlH4@NCMK-3 and their schematic representations (right). 
The particles with orange borders represent metallic Al. Scale bars, $50 \mathrm{~nm}$ and $5 \mathrm{~nm}$ (inset) c, Nitrogen adsorption/desorption isotherms at $77 \mathrm{~K}$ and d, Powder X-ray diffraction patterns of nanoconfined LiAlH4 in functionalized/non-functionalized mesoporous carbon scaffolds.
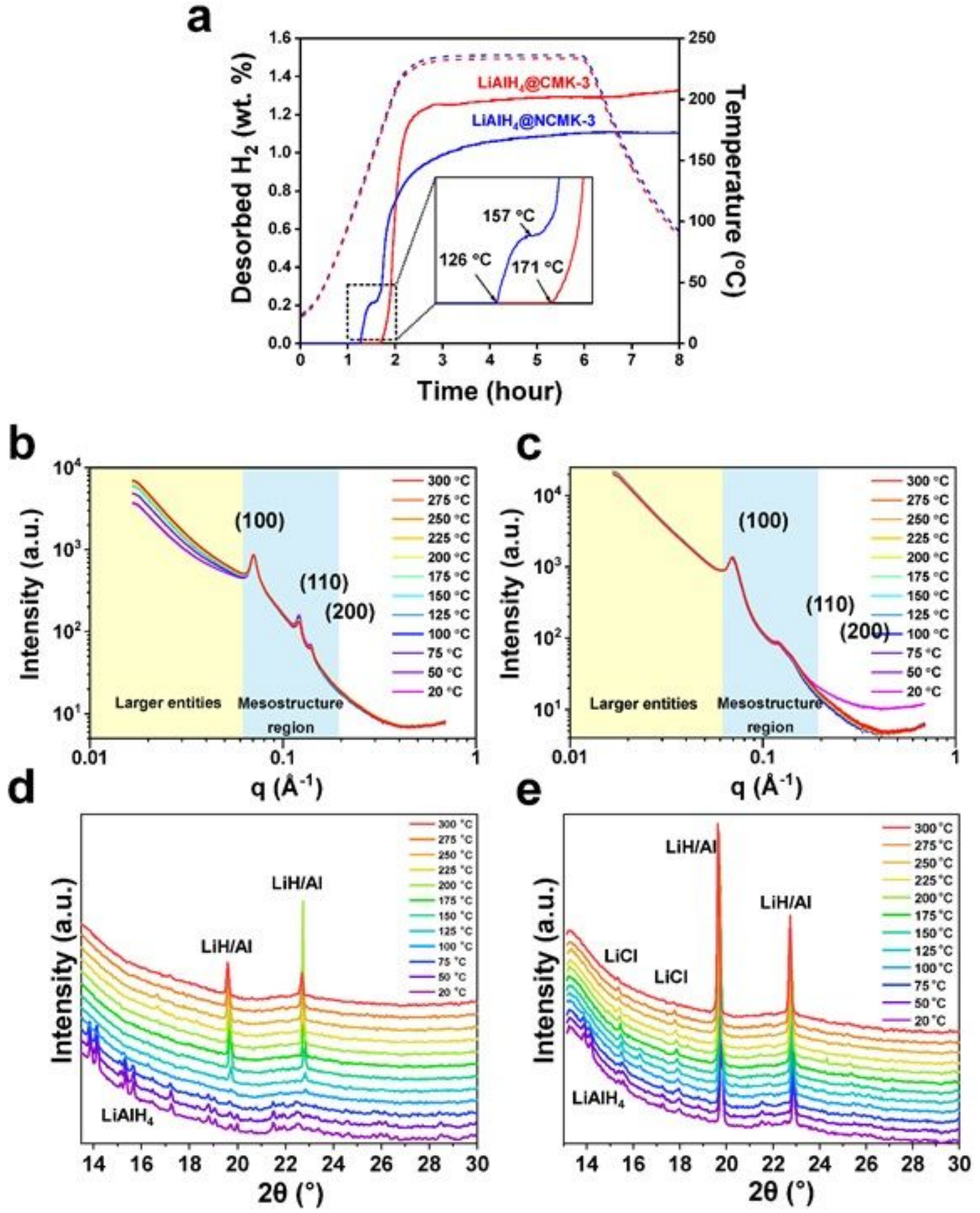

Figure 2

Characterization of mesostructures and $\mathrm{N}$-functionalities a, Hydrogen desorption kinetics curves of LiAlH4@CMK-3 and LiAlH4@NCMK-3. The dashed lines display the temperature profiles for the 
corresponding desorption curves. In-situ small-angle X-ray scattering (SAXS) with simultaneous wideangle X-ray scattering (WAXS) patterns of b, d, LiAlH4@CMK-3 and c, e, LiAlH4@NCMK-3 and upon heating from $20^{\circ} \mathrm{C}$ to $300^{\circ} \mathrm{C}$. Three mesostructure peaks from the samples can be assigned as (100), (110), and (200) indices based on hexagonal P6mm symmetry of CMK-3 type carbons.42

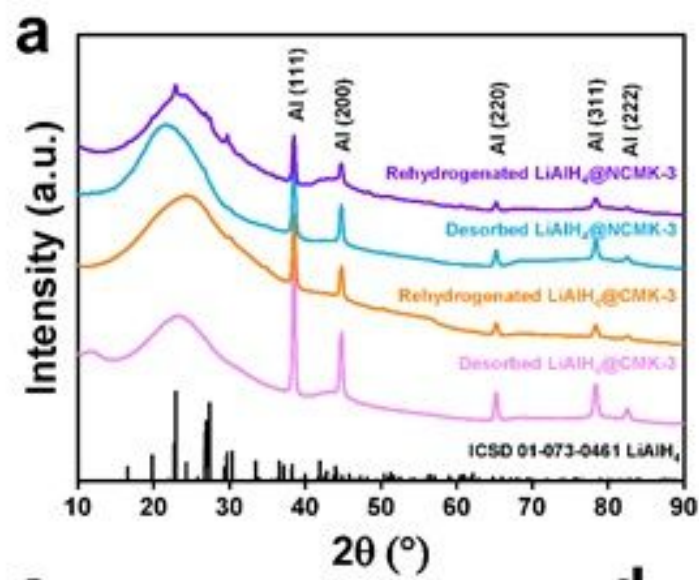

C

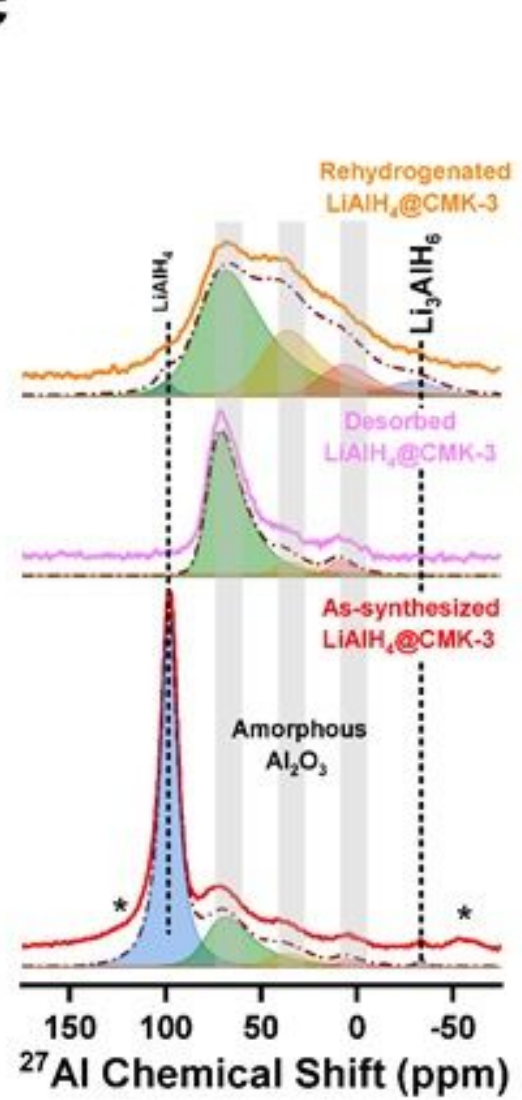

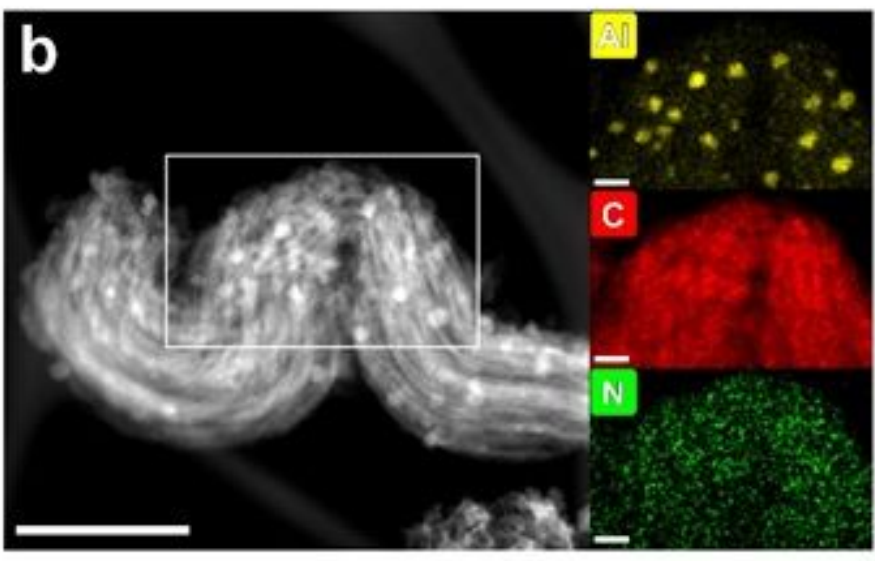

e

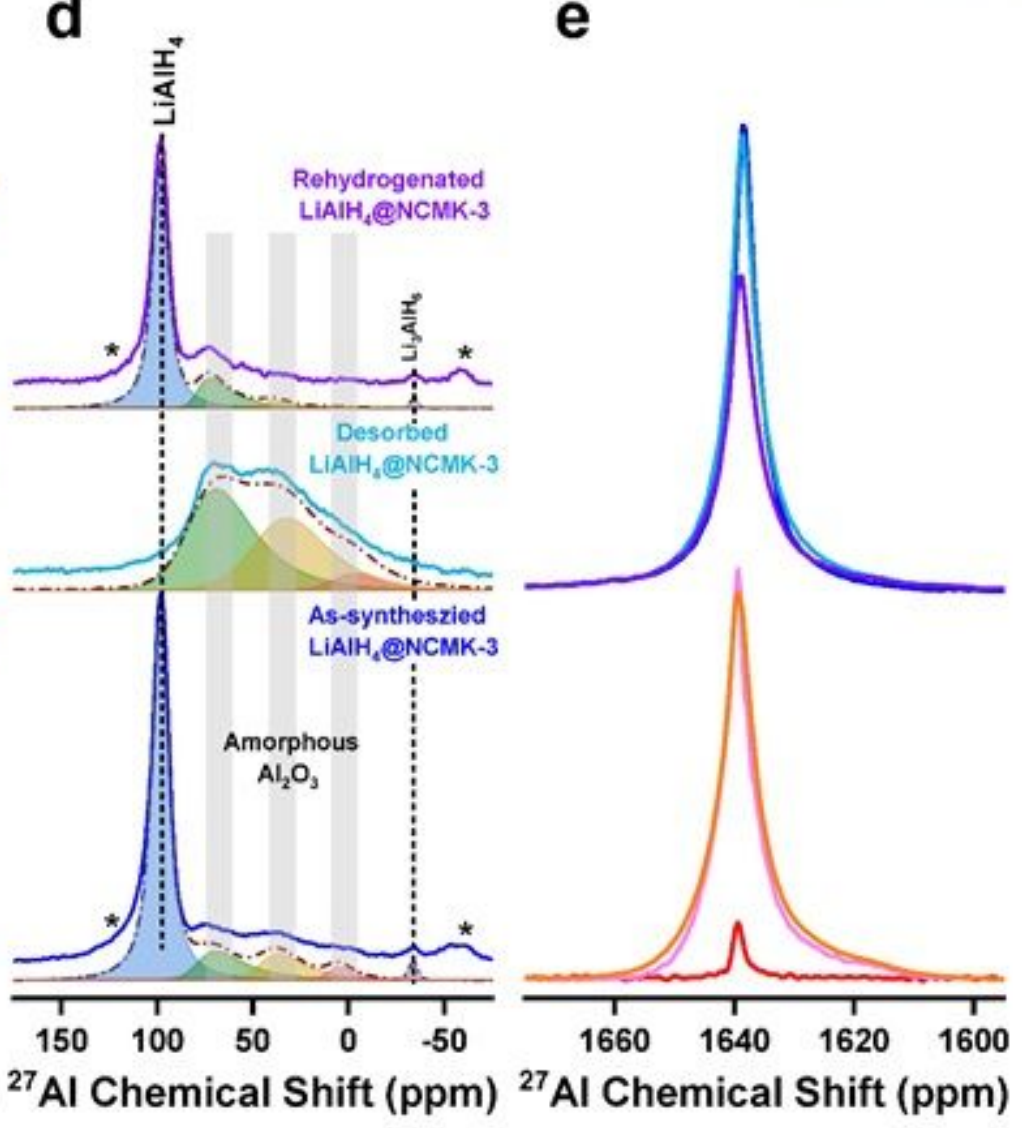

Figure 3

Rehydrogenation of nanoconfined LiAlH4 a, Ex-situ Powder X-ray diffraction patterns of LiAlH4@CMK-3 and LiAlH4@NCMK-3 b, High-angle annular dark-field scanning transmission electron microscopy 
(HAADF-STEM) image and energy dispersive X-ray maps of rehydrogenated LiAlH4@NCMK-3 Scale bars, $500 \mathrm{~nm}$ and $100 \mathrm{~nm}$ (inset). Ex-situ 27Al Magic angle spinning NMR spectra at low chemical shift range of c, LiAlH4@CMK-3, d, LiAlH4@NCMK-3, and e, at metallic Al signal range. In descending chemical shift the deconvolution components are LiAlH4 (blue), four coordinated Al in amorphous Al2O3 (green), five coordinated $\mathrm{Al}$ in amorphous Al2O3 (orange), six coordinated Al in amorphous Al2O3 (red).

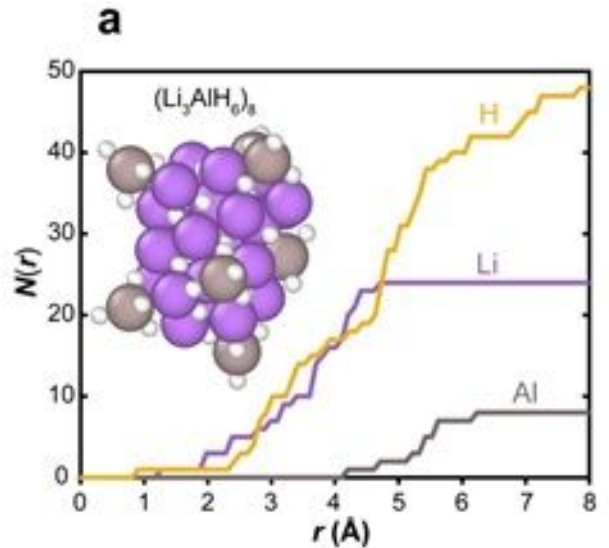

c

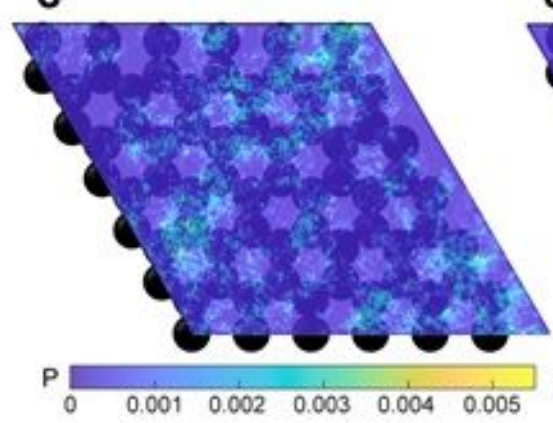

d

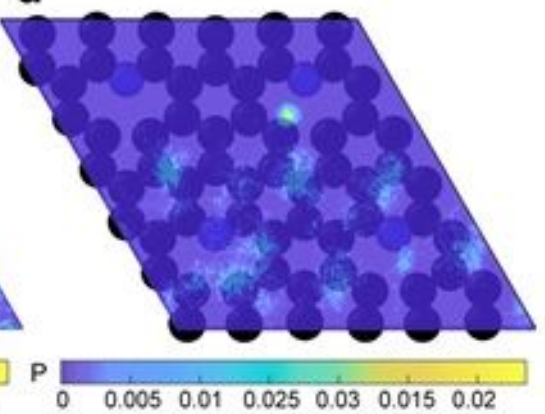

b

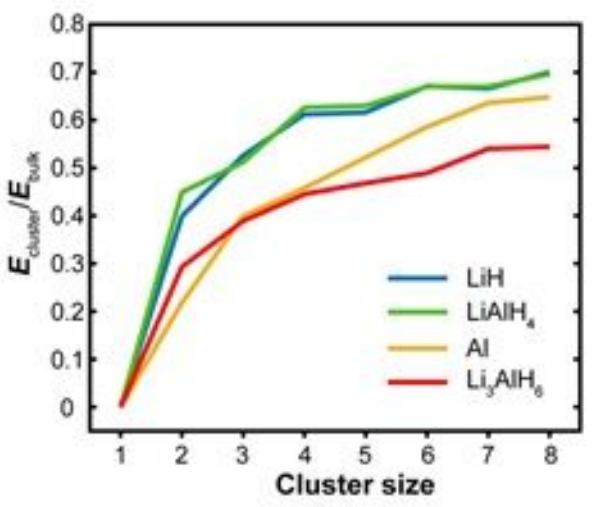

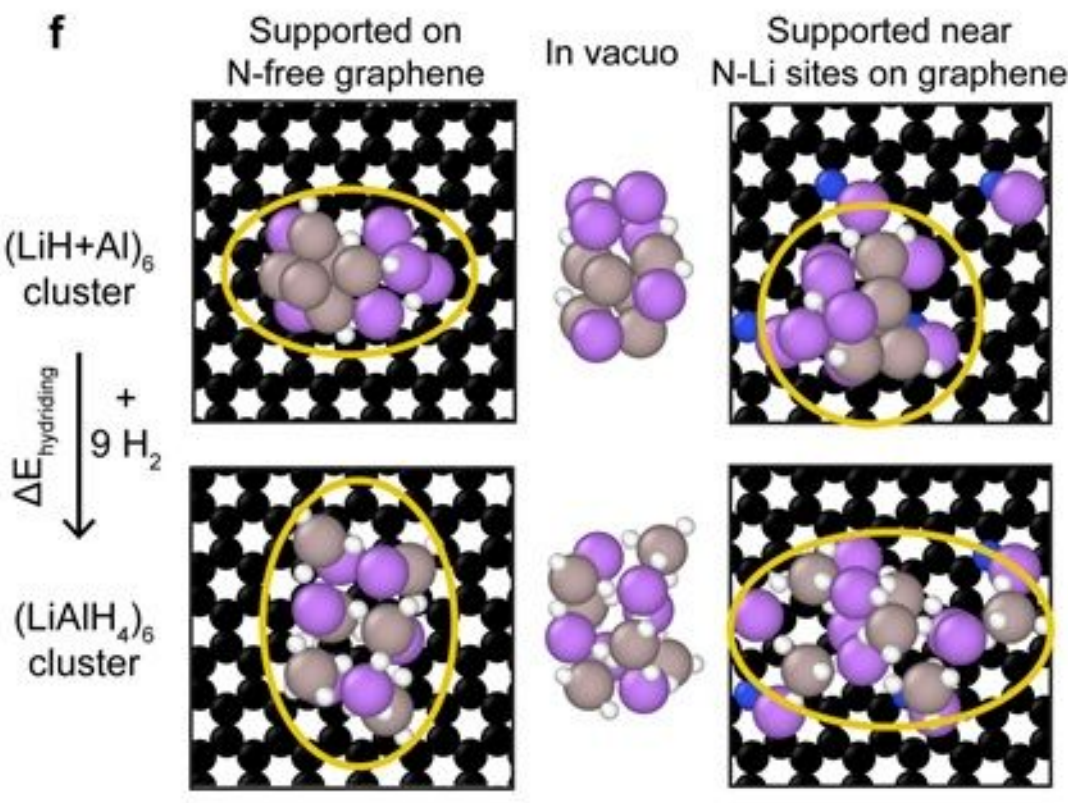

Figure 4 
Theoretical study regarding clusters of LiAlH4-related compounds and LiAlH4-scaffold interactions -a, Integrated atomic number density $\mathrm{N}(\mathrm{r})$ as a function of distance $\mathrm{r}$ from the center of mass of an isolated (Li3AlH6)8 cluster. The inset shows the corresponding relaxed cluster geometry. b, Ratio of molar formation energies (referenced to an isolated molecular unit) of isolated clusters of varying size versus bulk compounds (Ecluster/Ebulk) for key reaction intermediates. c \& d, Probability density of Li atoms in a (LiAlH4)8 cluster on (c) pristine graphene versus (d) graphene with a pyridinic $\mathrm{N}$ defect, averaged over the AIMD simulation trajectory. e, Electronic density of states of pure graphene and pyridinic N-doped graphene before and after incorporation of ( $\mathrm{LiAlH} 4) 6$. f, Relaxed geometries of ( $\mathrm{LiH}+\mathrm{Al}) 6$ (left panels) and (LiAlH4)6 (right panels) clusters on pristine pristine graphene (top panels) versus the pyridinic defect (bottom panels). $\mathrm{H}, \mathrm{Al}, \mathrm{Li}, \mathrm{C}$, and $\mathrm{N}$ atoms are shown in white, gray, purple, black, and blue, respectively.

\section{Supplementary Files}

This is a list of supplementary files associated with this preprint. Click to download.

- SILIAIH4CMKNatMaterFinal.docx

- TOC.jpg 